\title{
2798. The effect of noise on the comfort of passengers inside the tramway and its impact on traffic congestion in the urban area
}

\author{
Mouloud Khelf ${ }^{1}$, Salim Boukebbab ${ }^{2}$ \\ Laboratoire Ingénierie des Transports et Environnement, Faculté Science de la Technologie, Université des \\ Frères Mentouri Constantine 1, Campus Universitaire Zarzara 25017 Constantine, Algerie \\ ${ }^{1}$ Corresponding author \\ E-mail: ${ }^{1}$ mouloud.khelf@umc.edu.dz, ${ }^{2}$ boukebbab@yahoo.fr
}

Received 20 January 2017; received in revised form 29 July 2017; accepted 17 August 2017

DOI https://doi.org/10.21595/jve.2017.18196

Abstract. The tramway is a mean of transport which is used frequently in many cities around the world, because it improves the offer of public transport through its important capacity of transporting. This may ameliorate the state of road traffic by reducing the number of vehicles along the tram line. Despite these advantages, there are some problems related to users' comfort like the noise caused during the operation. This study is focused on the human perception of the noise levels detected inside the tramway. The objective of this work is to identify and analyze the level of noise detected inside tramway, to know in which cabin and section the high noise is recorded, to find the causes and to show if the measured noise influences the comfort of passengers. For that, noise measurements are taken in all cabs and along the tram line. The results show that the levels of noise inside the seven cabins is different. The high noise is detected in the motorized cabins and in many sections, like the curves and also in other sections. The results show also that this noise affects negatively on the comfort of passengers. Finally, different solutions that can contribute to reduce effectively the noise to make the tram more comfortable and efficient to relieve traffic congestion in urban areas are presented.

Keywords: tramway, public transport, noise, traffic, congestion, urban areas.

\section{Introduction}

In recent years, there has been an increasing interest in environmental noise, particularly noise caused by the different means of transport [1-3]. It's a severe problem, because it has negative impacts on the humans' health $[4,5]$. Several factors cause the noise in the urban environment, among these sources, road traffic, trains and certainly the tramways $[5,6]$.

Many studies have focused on the noise caused by the tramway, because it is a cause of nuisance for urban population [5, 7-13]. In addition, huge efforts are made by the tram manufacturers to lower this factor inside and outside the vehicle [14].

The tramways are widely used to relieve congestion in urban area. This contributes to decrease the noise of vehicles in neighboring homes and to reduce $\mathrm{CO} 2$ emissions $[15,16]$, and that what have led to the restoration of trams around the world [17]. However, the comfort of passengers is strongly affected by the noise inside the tram [18]. It is a source of annoyance not only for the inhabitants [19-21] but also for users. For this reason, it's necessary to decrease the level of noise inside the tramway and in the neighboring of railways [22].

Furthermore, it's important to predict the future noise levels [23] and to take into account this constraint during the construction of new lines of the tram in cities [24]. That will encourage people to use the tramway more than their particular cars because the tram will be more efficient and comfortable. This will help to reduce congestion and accidents in the urban areas [25].

This paper will focus on the annoyance caused by the noise inside tramway. The aim of This investigation is to determine the noise and to analyze the factors that cause it inside every cabin of the tram and along the tram line. This work also shows the opinion of passengers about this noise, its effect on their comfort and on their mode choice of transportation. 


\section{The case study}

This section introduces the area of study and presents the problems relate to the operation of tramway. In addition, to show the impact of this last on the road traffic and its effect on the level of noise inside tramway and in city.

\subsection{Presentation of the tram line}

During the last five years, the number of kilometers of urban railways built in Algeria has been tripled. A tramway network has been installed in three Algerian cities with 105 trams and other projects are on construction in many other cities [26]. Constantine's city is one of these three cities. The line forms a north-south axis. It connects the hyper center of the city from Benabdelmalek station to the suburban zone of Zouaghi Slimane. Along of $8 \mathrm{~km}$, the line serves 10 stations and powered by an electric energy by an overhead contact line LAC. The tramway traffic has its own path (excluding crossroads) and it is designed for a lifetime of 30 years [27].

\subsection{Problems caused by the exploitation of the tramway}

The location of the tram line and its stations makes it less accessible for a part of the population and also reduces the road's capacity since that some lanes are exploited to construct the railway. The tramway passes over the two strategic intersections every 3 or 5 minutes and that produces congestion and aggravate the traffic state, this increase noise inside and outside tramway. This bad exploitation with high tram traffic causes a probable reduction in the lifetime of the track and the rolling stock. This will increase noises that hamper the tramway users and the inhabitants [18]. The rail is among of the factors that affect the level of noise inside the cabins of tramway [28].

The optimal management of tramway and road traffic is necessary to increase the lifetime of the rail, to reduce congestion and to ameliorate the traffic state. The tramway will be more attractive with less noise inside cabins and outside it. Road users who will take the same route of the tram will park their vehicles and take it because the tram is comfortable and fast compared to buses and their vehicles [29]. This will decrease the flow of vehicles in these two crossroads and contribute to relieve congestion and reduce the noise in city.

\section{Architecture of the tram and characteristic}

In order to reduce the noise and make the tramway more comfortable, new trams are developed with low-floor and with auxiliary materials on the roof [30]. The proposed vehicle is from the CITADIS range, under reference Alstom CITADIS 402, its type is $100 \%$ low-floor, it is $75 \%$ motorized vehicle and it has a total capacity of 302 passengers.

The vehicle is bidirectional and it is expected to operate as a single unit. The tram is composed of seven articulated sections. The base vehicle Alstom CITADIS 402 includes the following modules:

- 2 motorized cabin (M1 et M2);

- 1 motorized nacelle (NM) and 1 carrier nacelle(NP);

- 3 suspended central section (cars-bodies) (C1, C2 and CC) [31].

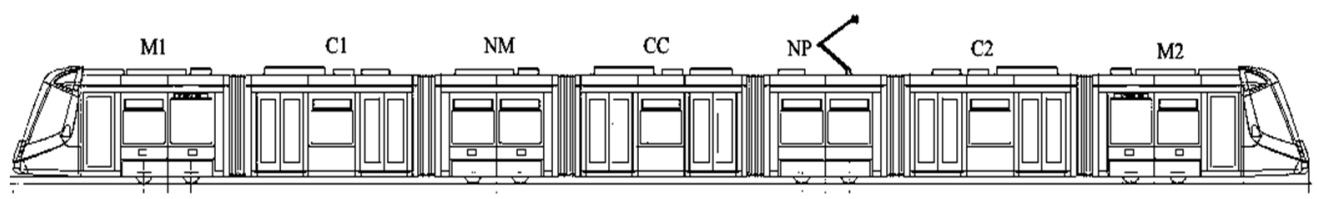

Fig. 3. Architecture of Constantine's tramway

The vehicle section is curved to the radius of 10 meters. The external width is $2650 \mathrm{~mm}$ to 
optimize the constraints of maintain and comfort in the right seats and interior width of $2.490 \mathrm{~m}$. The length of the vehicle is 43.763 meters; this value is likely to change very slightly with the finalization of the cabin aesthetics. The proposed width, combined with the length of the vehicle, enables an important capacity and offer comfort to passengers.

The Constantine's tramway contains 4 bogies which are three motorized bogies and one bogie carrier. The motor is a three-phase asynchronous squirrel cage [31].

\section{Track conception criteria}

In urban areas, the rails used in Constantine are mainly grooved rails, in order to be drowned in the roadway. The excitement wheel rail is among the major sources of noise and vibration inside the tram. The track design is based on the following constraints:

- Users comfort, security of passenger, level of noise and vibration;

- Maximum speed along the track layout;

- Simple construction and Simple maintenance [32].

The features of the soil and track play major role in the degree of noise and vibration [33]

\section{Traction system}

The traction system of tram includes:

- The socket by pantograph bow fitted with carbon bands;

- The protector;

- The main circuit breaker (DJ) that puts all the equipment under voltage but opens automatically in case of short circuit to protect the rest of the components;

- The static converter (CVS) which can produce from $750 \mathrm{~V}$;

- The contact line, three-phase alternating voltages or continuous, variable amplitude;

- The traction motors;

- The return brushes of the line current and setting the potential of rail vehicles, each of these functions being provided by separate devices housed in the wheels [34].

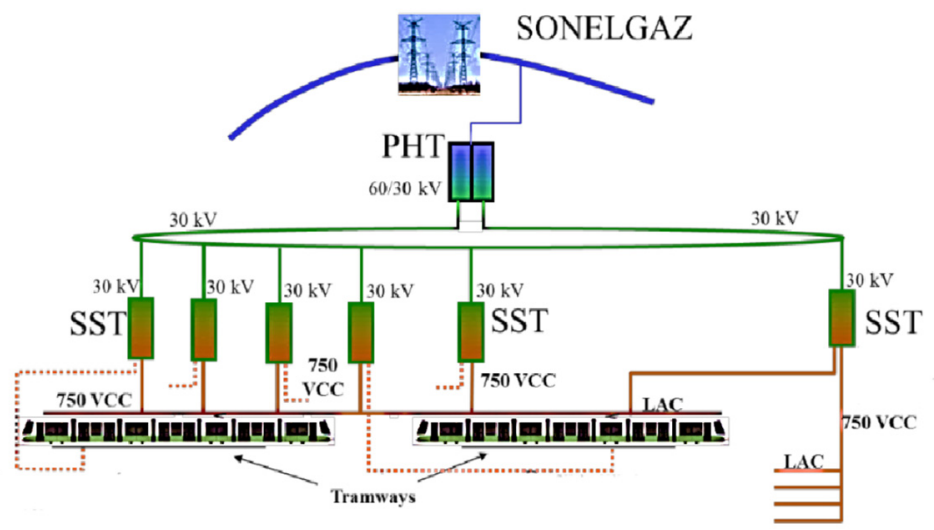

Fig. 5. System of traction energy of Constantine tramway

\section{The noise measurements inside the tram}

\subsection{The norms of noise inside Constantine's tram}

The noise measurement conditions are defined by the standards NF S 31-028 for the interior of the vehicle. The sound pressure level, measured in the passenger compartments, on an empty vehicle in running order is: 
- Noise level is less than $62 \mathrm{~dB}(\mathrm{~A})$ measured for a period of 30 seconds on a stationary vehicle, which may be greater than $3 \mathrm{~dB}(\mathrm{~A})$ below the cooling units in refrigeration mode.

- Noise level is less than $72 \mathrm{~dB}(\mathrm{~A})$ measured for 30 seconds, on a vehicle traveling at a speed of $50 \mathrm{~km} / \mathrm{h}[35]$.

\subsection{The experimental measurement step}

To measure the noise level inside the tramway, we have used a digital Sonometer CA832. The measurements are carried out along the tram line in both directions of rotation and in all tram cabs. Measures are taken in many days and in different hours.

We have taken them in everyone $\mathrm{km}$ where each one was cut into three points of measurement in order to miss any section that makes a lot of noise. We have measured every cab three times in both directions in all the section to confirm the level of noise and the causes that lead to it in all cabs of the tram. Passengers were silent in each cab to take the measures in the best conditions and to record the real value of the sound.

\subsection{The results of experimental measurement step}

The graphs below represent the noise measurements inside the seven tram cabs in both directions of the line. The first itinerary is from Zouaghi Slimane station to Benabdelmalek station, and the second one is from Benabdelmalek station to Zouaghi Slimane station.

We notice that the cabins with bogies make more noise than suspended central sections $(\mathrm{C} 1, \mathrm{CC}$ and $\mathrm{C} 2)$. On several sections of the line, the noise is higher than the minimum and maximum values measured inside the tram before its official operation. The source of the noise in the curves and in sections which contain many stations is mainly associated to the bogies and the auxiliary equipment on the roof. The tram passes in these sections in both directions with a low velocity between $7 \mathrm{~km} / \mathrm{h}$ and $30 \mathrm{~km} / \mathrm{h}$. The noise in these sections is between $65 \mathrm{~dB}(\mathrm{~A})$ and $79 \mathrm{~dB}(\mathrm{~A})$.

The second source of noise is related to the wheel-rail contact. It's detected when the velocity is between $40 \mathrm{~km} / \mathrm{h}$ and $60 \mathrm{~km} / \mathrm{h}$. This noise is very high and it happens in some sections in both directions at $83.1 \mathrm{~dB}(\mathrm{~A})$. Many trams have a loud noise that has reached $88.9 \mathrm{~dB}(\mathrm{~A})$, this value is very elevated for a new Citadis tramway. From here, it was noticed that the noise in the interior of the tram increases proportionally with its velocity.

The graph shows that the section between the third kilometer, the fifth kilometer and the first kilometer section for itinerary 1 (the last kilometer section for itinerary 2) are those sections that contain a very high noise level. These are the sections that disturb the passengers of the tramways in both itineraries. The measures below were carried out at the presence of the passengers. These last were silent during the measurements. Some other experiments were done when passengers behave normally. The result shows an increase of the noise between 5-10 $\mathrm{dB}(\mathrm{A})$ and $15 \mathrm{~dB}(\mathrm{~A})$ in the most critical situation. This increase doesn't only depend on the number of the passengers inside the tram, but also of their behavior inside the tram.

In addition, when the number of passengers increases, the number of tram operating along the line increases. Otherwise, the number of trams is constant. For a high average of 18500 passengers per day, the trams are used every 3 minutes and every 5 minutes. We notice that the supply was three times higher than the demand. Therefore, this exploitation will degrade rapidly the lifetime of railway and also the rolling stock. This issue will cause a bad contact between the wheel-rail and the noise will increase.

Finally, there is another source of the noise inside the tramway, which is the sound of the passenger information system. This sound is very strong because it reaches $99 \mathrm{~dB}(\mathrm{~A})$, it is repeated during 1 minute for each station. 

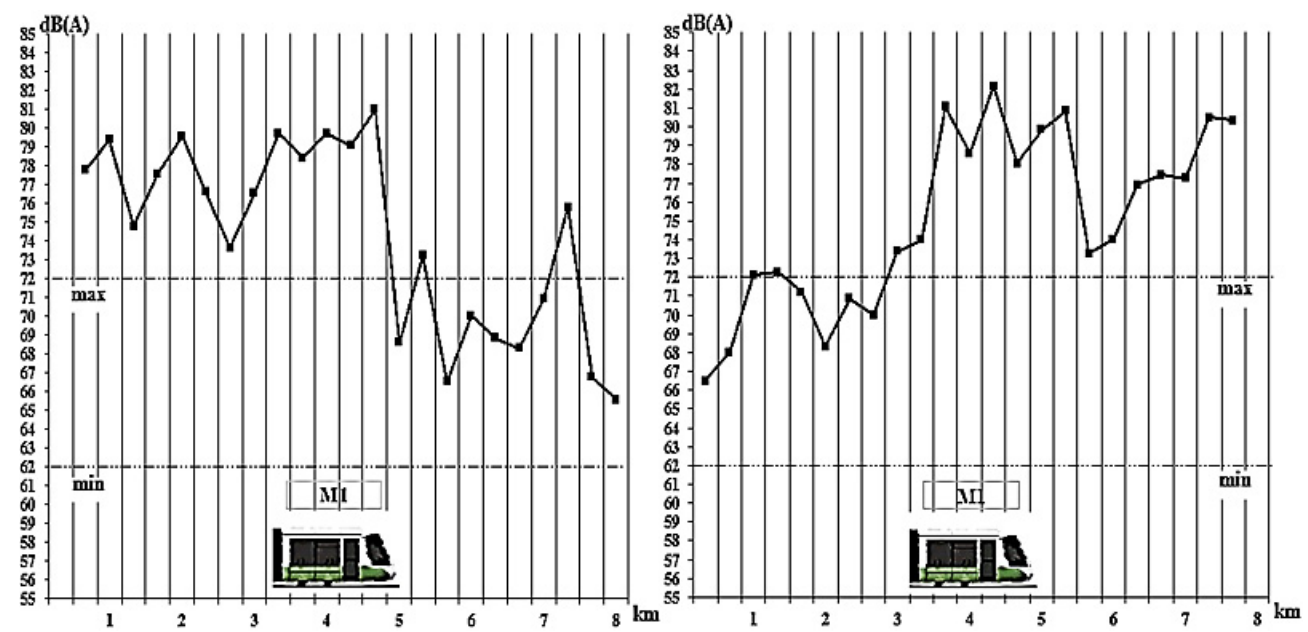

Fig. 6. Noise measurements of itinerary 1 and itinerary 2 for the cab M 1
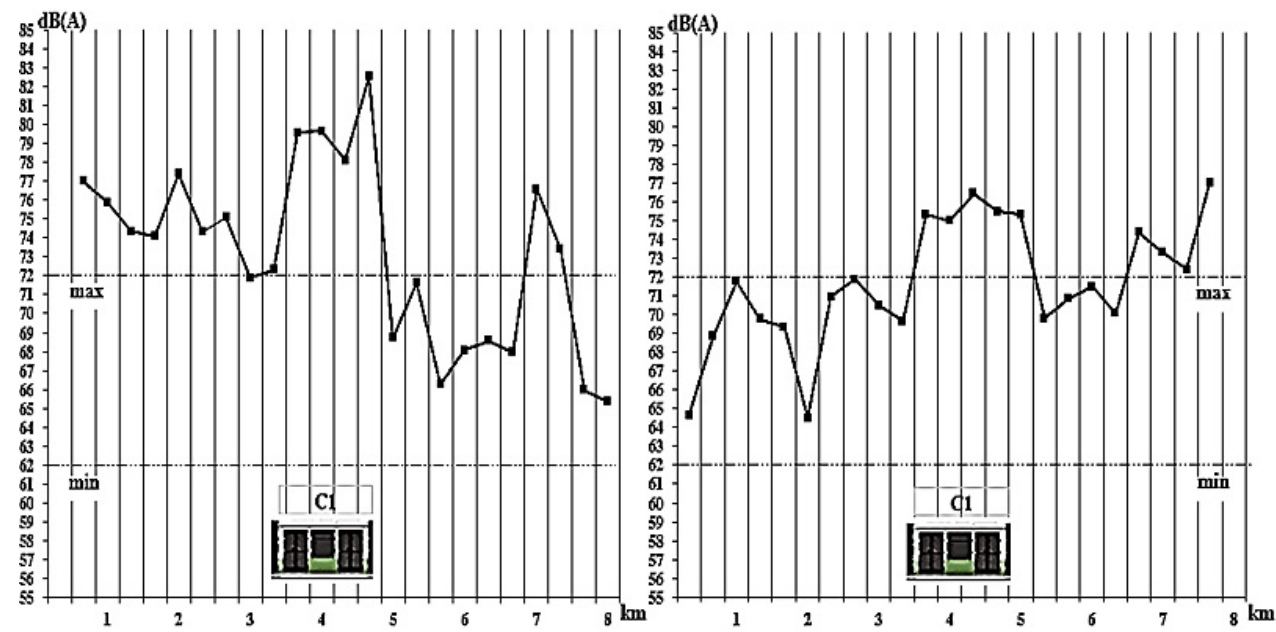

Fig. 7. Noise measurements of itinerary 1 and itinerary 2 for the cab $\mathrm{C} 1$
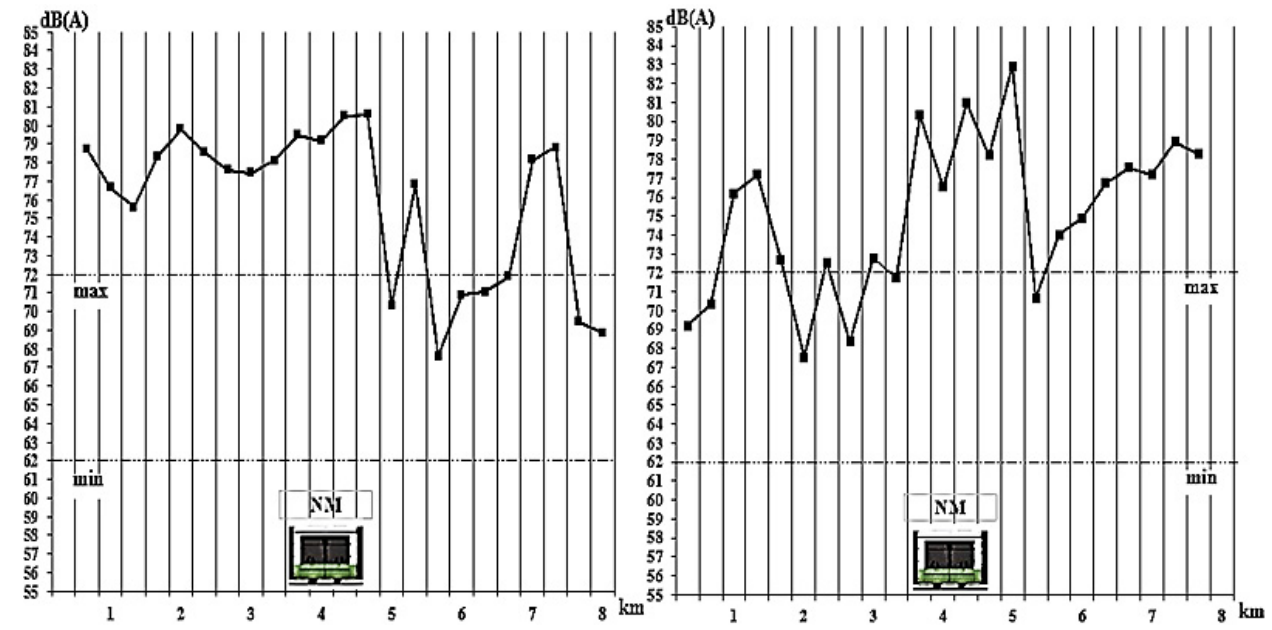

Fig. 8. Noise measurements of itinerary 1 and itinerary 2 for the cab NM 

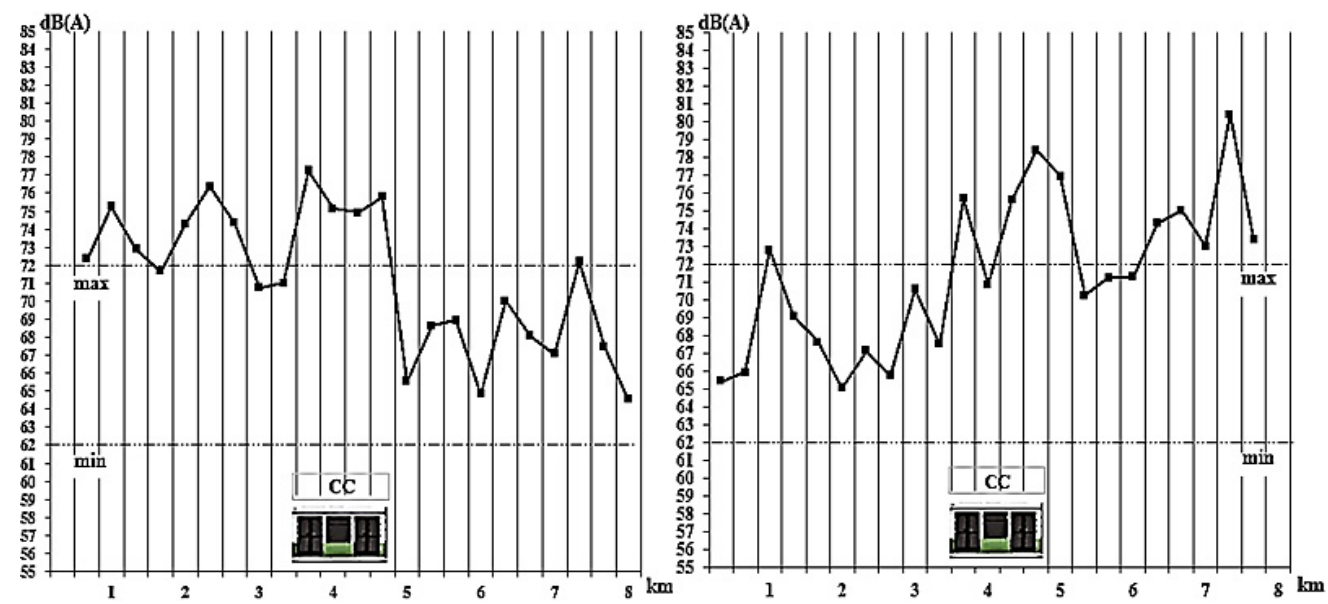

Fig. 9. Noise measurements of itinerary 1 and itinerary 2 for the cab CC
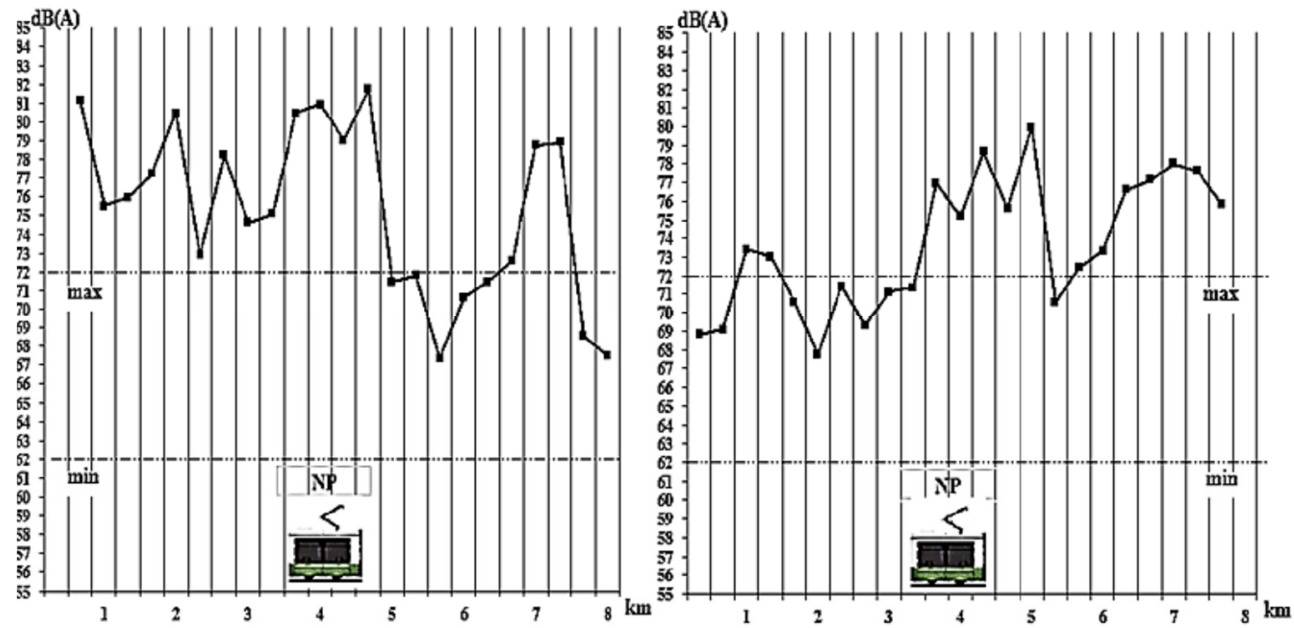

Fig. 10. Noise measurements of itinerary 1 and itinerary 2 for the cab NP
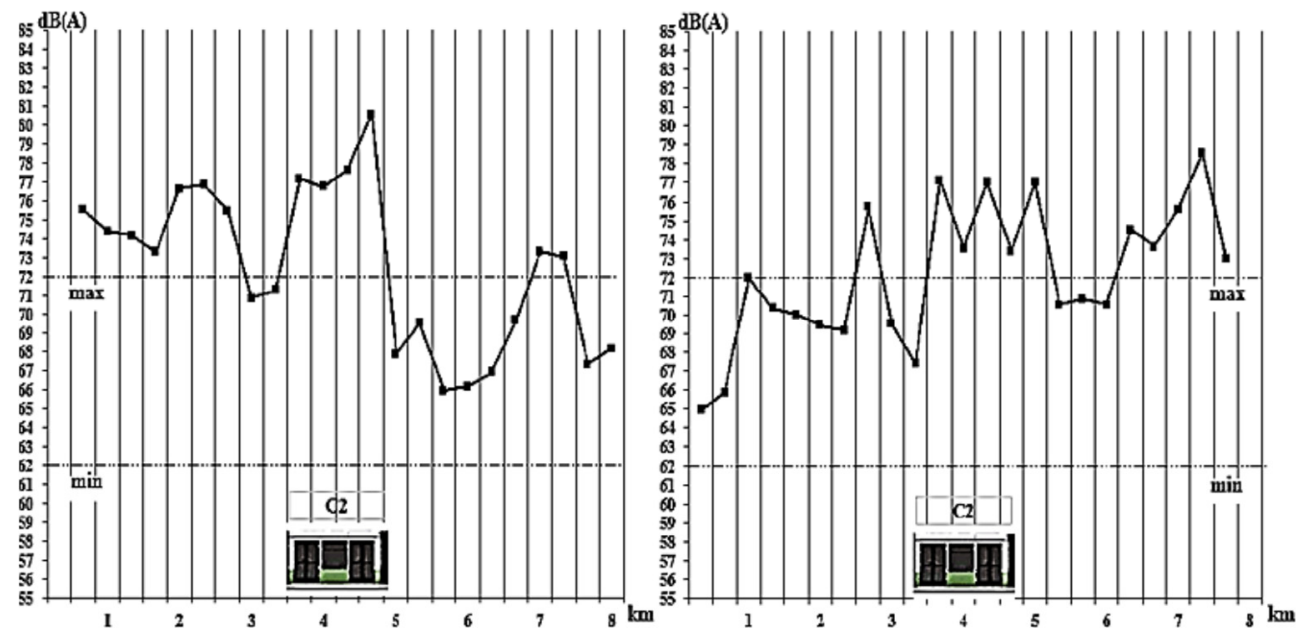

Fig. 11. Noise measurements of itinerary 1 and itinerary 2 for the cab $\mathrm{C} 2$ 

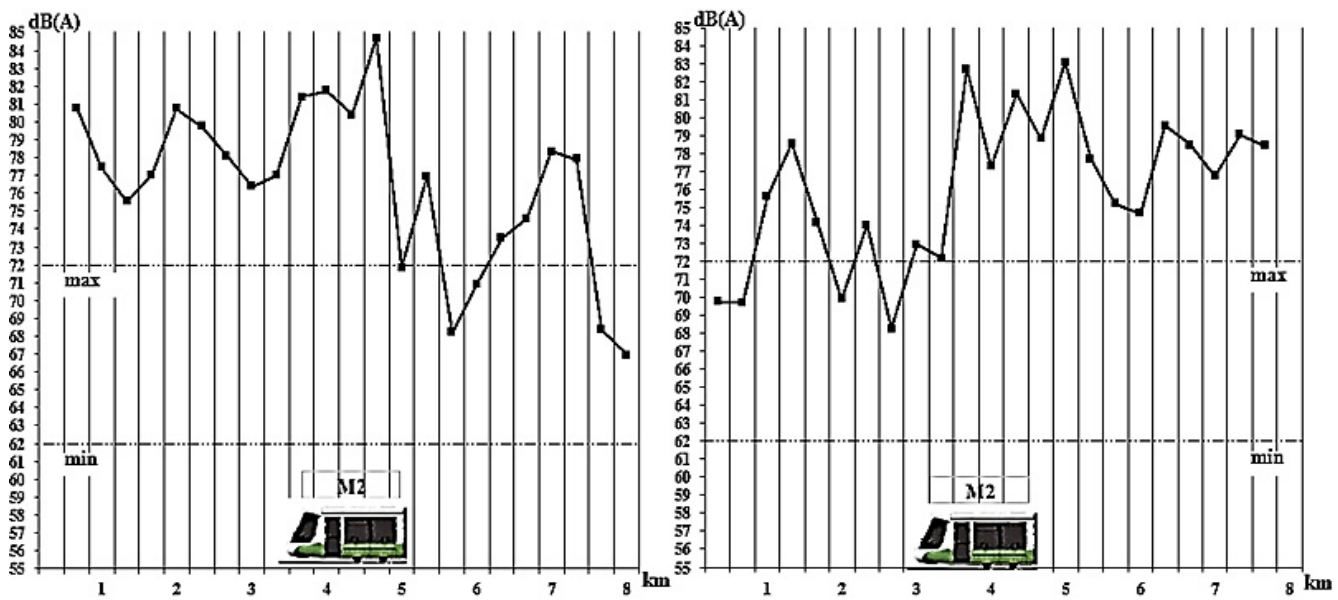

Fig. 12. Noise measurements of itinerary 1 and itinerary 2 for the cab $M 2$

\section{Survey results}

This survey is made to know if the detected noise at the sections along the line and in different cabs of the tram affects the comfort of passengers or not. It was conducted in December 2016 at several times of the day. So, a random sample of 250 passengers was selected inside the tram and in its stations. Nearly the half of users of the tram, men and women of all age categories, admit that they are disturbed by the noise of friction caused by the contact between the wheel and the rail since it can last for 30 seconds in some sections; and the noise made by equipment of the roof of the cabins when the tram crosses some curves.

Fig. 13 represents the response of the tram users who are of both genders, male and female and of all age categories. We observe on the histogram that $46.80 \%$ are bothered by the noise and this dissatisfaction rate is very high.

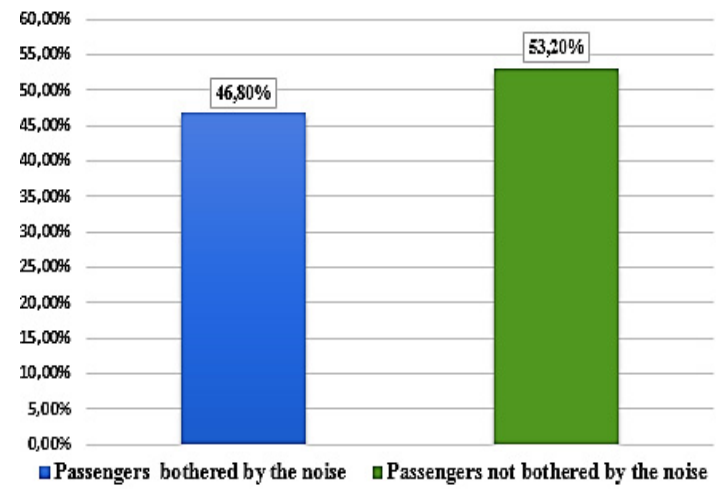

Fig. 13. Overall sample analysis

In Fig. 14 we notice that $47.71 \%$ of women and $46.10 \%$ of men are not satisfied of the disturbance caused by the noise inside the tram. Therefore, it is about half of women and men responded to the questionnaire that they are very annoyed by this noise. In order to validate these conclusions, we test separately:

Null hypothesis $H_{0}: p=1 / 2$ versus $p>1 / 2$, where $p$ is the probability that a woman is annoyed by the noise. $H_{0}$ means: there is the as much woman bothered by the noise as woman who are not. The chi-square test statistic is calculated by using the equation: 
$D^{2}=\sum_{i=1}^{2} \frac{\left(N_{i}-\frac{100}{2}\right)}{\frac{100}{2}}$

It follows a Chi-squared distribution with a degree of freedom equal to one. $N_{i}$ is the observed frequency, and 100/2 is the expected frequency under the null hypothesis.

We will compare the value of the test statistic $D^{2}$ to the critical value $d_{\alpha}$. We reject the null hypothesis $H_{0}$ if $D^{2}>d_{\alpha}, d_{\alpha}=3.841$ if $\alpha=0.05$. After calculation, we get:

$D^{2}=0.2098$.

We see that $0.2098<3.841$, so we accept the null hypothesis $H_{0}$.

The same thing to the variable men since that the sum of the column is equal to $100 \%$.

Null hypothesis $H_{0}: p=1 / 2$ versus $p>1 / 2$, where $p$ is the probability that a man is annoyed by the noise. $H_{0}$ means: there is the as much man bothered by the noise as man who are not:

$D^{2}=0.6084$

We have $0.6084<3.841$, for that we accept the null hypothesis $H_{0}$.

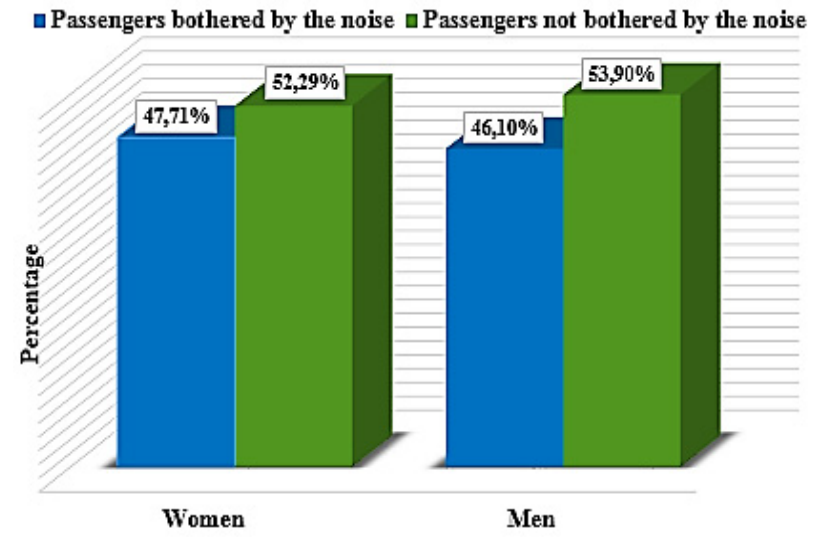

Fig. 14. Sample analysis of passengers by gender

Fig. 15 shows the sample according to the age of the passengers. The main categories of users who are aged of between 18-36 years old corresponding to the category of young people and who are between 37-55 years old corresponding to the category of workers. We observe that two categories of age are bothered by the noise inside the tram, young and adult people who are aged of between 18-36 years old and 37-55 years old because these categories use always tram.

1) For the first category $18-36$.

Null hypothesis $H_{0}$ : there is the as much persons bothered by the noise as persons who are not between 18 and 36 years old.

$D^{2}=0.1681$. We have $0.1681<3.841$, for that we accept the null hypothesis $H_{0}$.

2) For the second category $37-55$.

Null hypothesis $H_{0}$ : there is the as much persons bothered by the noise as persons who are not between 37 and 55 years old.

$D^{2}=0.033124$. We have $0.033124<3.841$, for that we accept the null hypothesis $H_{0}$.

We observe that the category of old people is not bothered by this noise like the other two categories. To validate this, we take: 
Null hypothesis $H_{0}$ : there is the as much persons bothered by the noise as persons who are not between 56 and 75 years old.

$D^{2}=11.115556$. We have $11.115556>3.841$, for that we reject the null hypothesis $H_{0}$.

There is much persons who are not bothered by the noise than who are in this category.

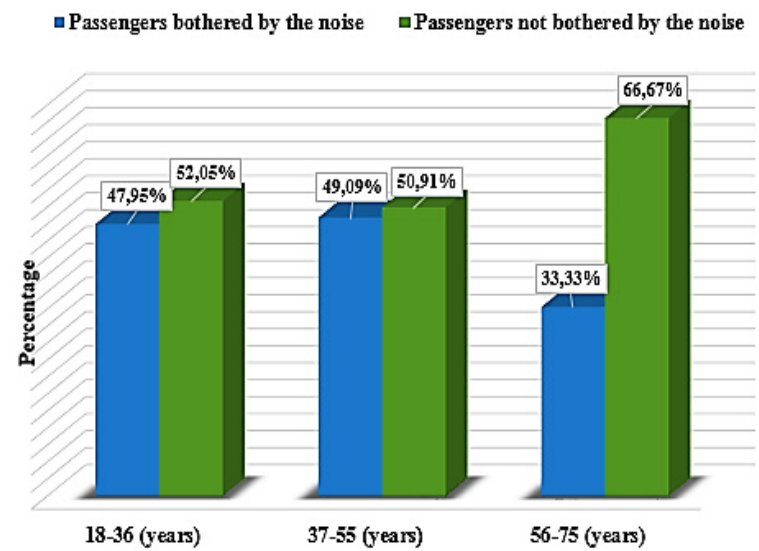

Fig. 15. Sample analysis of passengers by age

\section{Conclusions}

In this paper, the problem of noise emissions of tramway is tackled. Contrary to previous works, this one is realized inside the tram in order to measure the noise felt by the passengers. The purpose of the current study was to determine if the comfort of passenger is affected by this noise. Moreover, to show if that may influence their choice for means of transport and its impact on the road traffic.

The results of this investigation show that the rail, rolling stock like bogies and the traction system like equipment on the roof, are the main causes of noise inside the tram. It was also shown that the noise in the interior of the tram increases proportionally with its velocity. It is also noticed that a non-optimal exploitation will degrade rapidly the lifetime of railway and also the rolling stock. This issue will cause a bad contact between the wheel-rail and the noise will increase.

This study has found also that the number of passengers and especially their behavior affect the noise levels inside cabins.

The conducted investigation has shown that almost half of users, men and women are disturbed by the noise. It affects negatively the comfort of young and adult people, because these categories use always tramway. This result will increase the level of congestion if the bothered population change the mode of transport. Otherwise, the high sound of passenger's information bothers passengers and also who works inside the tram. These last have testified that at the end of the day they have a headache due to this noise.

Several recommendations should be taken in order to reduce the noise inside tramways and increase the comfort of passengers. The exploitation timetable of tramway should be optimized taking into account the actual situation of road traffic, the lifespan of the rolling stock and the track. In order to increase this last and decrease congestion in important crossroads, the time between the tramways must be augmented. Rolling stock does not wear out quickly and the railway not rapidly degraded by the high traffic of the trams. The optimal management of the trams allows to better assign the passengers to the cabins and helps passengers to keep calm. This may avoid the increase of noise in the tram.

An effective maintenance should be applied to the rolling stock, the rail and traction equipment to keep them in a good state and to generate a less noise. Some technical recommendation must be applied to reduce the noise due to contact of the wheel and rail, like lubricating the rails and 
sending sand in the wheels by the driver when the tram passes across sections that make noise.

Using some materials that help to absorb the noise such as rubber plates and green belt along line sections where high noise is measured. It is also necessary to reduce speed in critical sections which contain a high noise level. The sound of the passenger information system should be adjusted around $65 \mathrm{~dB}(\mathrm{~A})$ to make the tram more comfortable for all users.

This study may be considered as a contribution to future works that aims at making the tramway more comfortable and more efficient. These two last factors make the tramway more attractive which will incite people to use it than other means and that will help to reduce congestion in urban areas.

\section{References}

[1] Paunović K., Belojević G., Jakovljević B. Noise annoyance is related to the presence of urban public transport. Science of The Total Environment, Vol. 481, 2014, p. 479-487.

[2] Portela B. S., Zannin P. H. T. Analysis of factors that influence noise levels inside urban buses. Journal of Scientific and Industrial Research (JSIR), Vol. 69, 2010, p. 684-687.

[3] Dudkin E. P., Andreeva L. A., Sultanov N. N. Methods of noise and vibration protection on urban rail transport. Procedia Engineering, Vol. 189, 2017, p. 829-835.

[4] Sandrock S., Griefahn B., Kaczmarek T., Hafke H., Preis A., Gjestland T. Experimental studies on annoyance caused by noises from trams and buses. Journal of Sound and Vibration, Vol. 313, Issues 3-5, 2008, p. 908-919.

[5] Panulinova E., Harabinová S., Argalášová L. Tram squealing noise and its impact on human health. International Journal Noise Health, Vol. 18, Issue 85, 2016, p. 329-337.

[6] Panulinová E. Input data for tram noise analysis. Structural and physical aspects of construction engineering. Procedia Engineering, Vol. 190, 2017, p. 371-376.

[7] Rylander R., Björkman M., Hrlin U., Sörensen S. Tramway noise in city traffic. Journal of Sound and Vibration, Vol. 53, Issue 3, 1977, p. 353-358.

[8] Öhrström E. Effects of exposure to railway noise - a comparison between areas with and without vibration. Journal of Sound and Vibration, Vol. 205, Issue 4, 1997, p. 555-560.

[9] Miedema H. M. E., Van Den Berg R. Community response to tramway noise. Journal of Sound and Vibration, Vol. 120, Issue 2, 1988, p. 341-346.

[10] Gidlöf-Gunnarsson A., Ögren M., Jerson T., Öhrström E. Railway noise annoyance and the importance of number of trains, ground vibration, and building situational factors. International Journal Noise and Health, 2012, Vol. 14, 59, p. 190-201.

[11] Cik M., Lercher P. Ground-borne vibrations, sounds and secondary airborne sounds from tramways: a psychoacoustic evaluation including health aspects. 43rd International Congress on Noise Control Engineering, 2014, p. 1-9.

[12] Lubica A., Jana J., Ludmila S., Zuzana S., Katarína H., Jana B., Andrea K., Alexandra F. Environmental noise and annoyance in the urban area at different time intervals. Applied Mechanics and Materials, Vol. 617, 2014, p. 110-115.

[13] Dratva J., Phuleria H. C., Foraster M., Gaspoz J. M., Keidel D., Künzli N., Liu L. J. S., Pons M., Zemp E., Gerbase M. W., Schindler C. Transportation noise and blood pressure in a populationbased sample of adults. Environmental Health Perspectives, 2012, Vol. 120, 1, p. 50-55.

[14] Uhl T., Wszolek W., Wszolek T., Karpinski J. Noise and vibration problems in tram design. Proceedings of Internoise, the 1999 International Congress on Noise Control Engineerig, USA, Vol. 1, 1999, p. 283-8.

[15] Abdo J. Construction of New Roads Infrastructures: the Solution of Congestion? Technical Collection Cimbéton T32. Center of Information about Cement and Its Applications, Paris, France, (in French).

[16] Forstall R. L., Greene P. R., Pick J. B. Which are the largest? Why lists of major urban areas vary so greatly. Tijdschrift Voor Economische En Sociale Geografie, Vol. 100, Issue 3, 2009, p. 277-297.

[17] Zeng A. Z., Durach C. F., Fang Y. Collaboration decisions on disruption recovery service in urban public tram systems. Transportation Research Part E: Logistics and Transportation Review, Vol. 48, Issue 3, 2012, p. 578-590.

[18] Burdzik R., Kuminek T., Mańka A., Myńczak J., Mikulski J. Research on vibroacoustic phenomena of tram vehicles for the changeable dynamics conditions. Vibroengineering Procedia, Vol. 3, 2014, p. 408-412. 
[19] Crayon Bleu Alipur's Report of Activities 2009. Field of Evaluation of Used Tyres. Aliapur, France, 2009, p. 35, (in French).

[20] Apte J. S., Bombrun E., Marshall J. D., Nazaroff W. W. Global intraurban intake fractions for primary air pollutants from vehicles and other distributed Sources. International Journal of Environmental Science Technology, Vol. 46, Issue 6, 2012, p. 3415-3423.

[21] Motyl M., Nowakowski T., Czechyra B., Firlik B. Certification requirements for tram noise measurements in terms of today's expectations in cities. WIT Transactions on Ecology and the Environment, Vol. 210, 2017, p. 591-596.

[22] Lakušić S., Ahac M. Rail traffic noise and vibration mitigation measures in urban areas. Technical Gazette, Vol. 19, Issue 2, 2012, p. 427-435.

[23] Mandula J., Salaiova B., Koval'akova M. Prediction of noise from trams. Applied Acoustics, Vol. 63, 2002, p. 373-389.

[24] Lakušic S., Haladin I., Ahac M. The effect of rail fastening system modifications on tram traffic noise and vibration. Shock and Vibration, 2016, https://doi.org/10.1155/2016/4671302.

[25] Dua Y., Zhao C., Zhang X., Sun L. Microscopic simulation evaluation method on access traffic operation. Simulation Modelling Practice and Theory, Vol. 53, 2015, p. 139-148.

[26] Segaudi L., Ecotiere D., Dutilleux G., Puymérail G. F. A local directivity for 3 French tramways. The 10th French Acoustic Congress, Lyon, 2010, (in French).

[27] General Presentation of the Transportation System. Source Entreprise Metro d'Alger (EMA), 2013, p. 80, (in French).

[28] Panulinová E., Harabinová S. Monitoring of tram traffic noise in the small curve radius. Applied Mechanics and Materials, Vol. 617, 2014, p. 120-123.

[29] Prud'homme R., Koning M., Kopp P. Substituting a tramway to a bus line in Paris: costs and benefits. Transport Policy, Vol. 18, Issue 4, 2011, p. 563-572.

[30] Pallas M.A., Lelong J., Chatagnon R. Characterisation of tram noise emission and contribution of the noise sources. Applied Acoustics, Vol. 72, Issue 7, 2011, p. 437-450.

[31] Functional Specification and General Technics for Rolling Stock. Source Entreprise Metro d'Alger (EMA), 2010, p. 12-14, (in French).

[32] General Presentation of the Transportation System. Source Entreprise Metro d'Alger (EMA), 2008, p. 24, (in French).

[33] Maldonado M., Chiello O., Le Houedec D. Propagation of vibrations due to a tramway line. Noise and vibration mitigation. Notes on Numerical Fluid Mechanics and Multidisciplinary Design, Vol. 99. 2008, p. 158-164.

[34] Georges Muller Railway Traction: Trams Systems, Operating and Design. Techniques of the Engineer Railway Infrastructure and Rolling Stock. Editions T. I., Vol. 2, 2007, p. 16, (in French).

[35] Transportation's System Contracts Documents 5 Rolling Stock. Source Entreprise Metro d'Alger (EMA), 2008, p. 30, (in French).

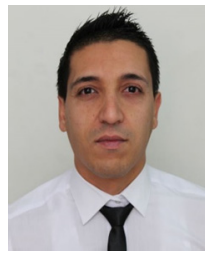

Mouloud Khelf had his Master degree in 2014 in mechanical engineering specialized in transportation engineering in University of Constantine 1, Algeria; he worked in (EPTP) public company for public works from 2014 to 2015 as a logistics and transport engineer. Starting from 2015 until now he is preparing for his Ph.D. degree in transportation engineering, his research is focused on problems related to traffic congestion in urban area. In 2016 he began to work as a teacher of directed works at department of Transport Engineering.

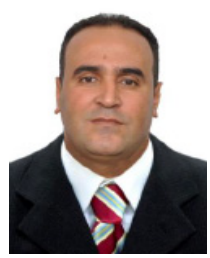

Salim Boukebbab has been graduated as an engineer on mechanical engineering from the University of Constantine, Algeria in 1989 to 1994. From 1994-1998, he joined the laboratory of Mechanics at the Higher National School of Arts and Métiers Aix-en-Provence, France which he received the Ph.D. degree on advanced mechanics. He worked at "CMT", which is a national company of production tractor and motor (1998-2001). He returned to the University of Constantine in 2001 and is currently Professor at Transport Engineering Department. 